\title{
A roda de conversa como instrumento de cuidado e promoção da saúde mental: percepção dos usuários dos CAPS
}

RESUMO | Objetivo: Descrever a percepção dos usuários de cada CAPS quanto à roda de conversa. Metodologia: Pesquisa transversal descritiva com abordagem qualitativa em que foi priorizada a fala dos usuários participantes por meio de entrevistas, observações sistemáticas e registro em diário de campo. Resultados e Discussão: Esse estudo nos mostrou que a roda de conversa se compõe como uma ferramenta terapêutica que auxilia na reabilitação dos usuários dos CAPS, reduzindo as tensões relacionadas às crises psicóticas e as recaídas do álcool e outras drogas no seu tratamento. Conclusão: A roda de conversa funciona como um dispositivo positivo para o cuidado e a promoção da saúde mental dos usuários dos CAPS.

Palavras-chaves: Reforma Psiquiátrica; Saúde Mental; Roda de Conversa; Promoção da Saúde Mental; CAPS.

\begin{abstract}
Objective: To describe the perception of the users of each CAPS regarding the conversation circle. Methodology: Descriptive cross-sectional research with a qualitative approach in which the speech of the participating users was prioritized through interviews, systematic observations and record in a field diary. Results and Discussion: This study showed us that the conversation wheel is composed as a therapeutic tool that helps in the rehabilitation of CAPS users, reducing tensions related to psychotic crises and relapses of alcohol and other drugs in their treatment. Conclusion: The conversation wheel works as a positive device for the care and promotion of the mental health of CAPS users.
\end{abstract}

Keywords: Psychiatric Reform; Mental Health; Circle of Conversation; Promotion of Mental Health; CAPS.

RESUMEN | Objetivo: Describir la percepción de los usuarios de cada CAPS con respecto al círculo de conversación. Metodología: investigación transversal descriptiva con un enfoque cualitativo en el que se priorizó el discurso de los usuarios participantes a través de entrevistas, observaciones sistemáticas y registro en un diario de campo. Resultados y discusión: Este estudio nos mostró que el círculo de conversación está compuesto como una herramienta terapéutica que ayuda en la rehabilitación de los usuarios de CAPS, reduciendo las tensiones relacionadas con las crisis psicóticas y las recaídas de alcohol y otras drogas en su tratamiento. Conclusión: La rueda de conversación funciona como un dispositivo positivo para el cuidado y la promoción de la salud mental de los usuarios de CAPS.

Descriptores: Reforma Psiquiátrica; Salud Mental; Rueda de Conversación; Promoción de la Salud Mental; CAPS.

\section{Layane Barbosa Amorim}

Enfermeira, Graduada pela Faculdade Estácio de Alagoas.

\section{Maria Rejane Santos}

Enfermeira, Graduada pela Faculdade Estácio de Alagoas.

\section{José Augustinho Mendes Santos}

Enfermeiro, Graduado pela Faculdade Estácio de Alagoas; Especialista em Urgência, Emergência e Intensivismo pela modalidade residência pelo Hospital Santa Cruz-HSC; Mestrando em Enfermagem pelo Programa de Pós-Graduação em Enfermagem da Escola de Enfermagem da Universidade Federal de Alagoas; Diretor Administrativo do Centro de Saúde de Feira Grande; Coordenador de Enfermagem do Pronto Atendimento $24 \mathrm{H}$ Eulina Lira da Silva.

Recebido em: 06/03/2020

Aprovado em: 07/03/2020
Camila da Paz Santos

Enfermeira, Graduada pela Universidade Federal de Alagoas, Mestre em Enfermagem pelo Programa de Pós Graduação em Enfermagem da Universidade Federal de Alagoas; Enfermeira Assistencial do Hospital Universitário de Largato.

\section{Fernanda dos Santos lochims}

Enfermeira, Graduada pela Universidade de Santa Cruz do Sul- UNISC; Especialista em Urgência, Emergência e Intensivismo pela modalidade residência pelo Hospital Santa Cruz-HSC; Mestranda em Educação pelo Programa de Pós-graduação em Educação da Universidade de Santa Cruz do Sul.

\section{Wanderson Alves Ribeiro}

Enfermeiro. Docente Substituto do Curso de Graduação, do Departamento de Enfermagem Fundamental da Escola de Enfermagem Anna Nery/UFRJ; Docente do Curso de Graduação em Enfermagem e PósGraduação de Emergência;Terapia Intensiva e Obstetrícia da UNIG; Mestre pelo Programa Acadêmico em Ciências do Cuidado em Saúde pela EEAAC/UFF.
INTRODUÇÃO

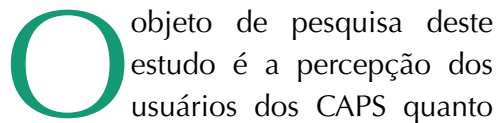
à roda de conversa. $\mathrm{O}$ interesse da pesquisa emergiu através das experiências proporcionadas pelas práticas da disciplina de Ensino Clínico VI - Saúde Mental, ocorridas no CAPS AD III de Maceió, ao observar as rodas de conversa que são realizadas entre os usuários dos CAPS e profissionais da saúde. Este estudo é relevante, porque torna possível a realização da abordagem do assunto acerca da roda de conversa como instrumento de cuidado e promoção da saúde mental na percepção dos usuários dos CAPS.

A roda de conversa surge como um espaço que possibilita uma escuta cuidadosa de participação coletiva e tem como finalidade abrir espaços para discussões, desabafos e funcionam como um meio de autoajuda, facilitando o diálogo entre 
os participantes e os profissionais. A roda
estimula um espaço livre de conversa, no qual os participantes se sintam a vontade para expressarem seus medos, suas angústias, seus momentos de tristeza e também de alegria e, assim, compartilhando suas experiências uns com os outros.

Durante muitos anos, o doente mental era ligado a um atendimento baseado no modelo hospitalocêntrico, os atendimentos a esses portadores de transtornos mentais eram realizados nas Santas Casas de Misericórdia, que eram instituições filantrópicas e religiosas que acolhiam esses enfermos, mas os atendimentos que eles recebiam eram precários, onde sofriam maus tratos, não tinham uma boa higiene, eram afastados de seus lares e submetidos a internações por tempos prolongados. E foi durante esse tempo, que eles eram excluídos da sociedade, tinham seus direitos humanos violados e viviam sob o modelo asilar, o qual era baseado na punição como o método de eletrochoque e contenção física ${ }^{(1)}$.

A reforma psiquiátrica teve início na década de 80 e vem provocando grandes mudanças no campo da saúde mental. Com o surgimento da reforma psiquiátrica, houve uma influência diretamente na assistência da saúde oferecida ao sujeito portador do sofrimento psíquico, e teve como o objetivo de transformar os manicômios, rompendo modelos e alcançando conviver com a loucura ${ }^{(2)}$.

A reforma surge desestabilizando e criticando o modelo dominante da assistência na saúde mental, criando novas crenças, novas leis, costumes à liberdade, e o direito de garantir uma assistência como um todo à saúde desses indivíduos ${ }^{(2)}$.

A partir do ano de 1989, foi proposta uma lei que regulamenta os direitos dos portadores de transtornos mentais, mas que só foi aprovada em 2001, a Lei n. ${ }^{\circ}$ 10.216/01 prevê a proteção e os direitos das pessoas com transtornos mentais e representa, no Brasil, um marco ao estabelecer a necessidade de respeito à dignidade humana a essas pessoas ${ }^{(3)}$.

A atual política teve como objetivos
A reforma psiquiátrica teve início na década de 80 e vem provocando grandes mudanças no campo da saúde mental. Com o surgimento da reforma psiquiátrica, houve uma influência diretamente na assistência da saúde oferecida ao sujeito portador do sofrimento psíquico, e teve como o objetivo de transformar os manicômios, rompendo modelos e alcançando conviver com a loucura ${ }^{(2)}$. uma mudança nos atendimentos que eram prestados aos doentes mentais, como a exclusão dos manicômios onde essas pessoas com transtornos mentais viviam sob condições desumanas, e foi durante essa década que houve a desinstitucionalização destes indivíduos que residiam nesses manicômios e a criação do Centro de Atenção Psicossocial - CAPS ${ }^{(2)}$.

Os CAPS foram substituídos pelo antigo modelo asilar e são compostos por equipes multiprofissionais que atendem as pessoas em sofrimento psíquico ou que fazem uso de álcool e outras drogas, e têm com objetivos a reinserção desses indivíduos na sociedade. O CAPS envolve ações que são realizadas individuais, com as famílias e em grupos, essas ações funcionam como dispositivos estratégicos para essas pessoas em sofrimento mental ou decorrente do uso de álcool e outras drogas ${ }^{(2)}$.

Uma das ações que são realizadas nos CAPS e que visa à promoção da saúde mental desses indivíduos é a roda de conversa, que serve como uma estratégia de ação da promoção da saúde mental e surge como um espaço que possibilita uma escuta cuidadosa de participação coletiva. A roda pode configurar-se como um espaço dialógico alternativo de escuta e de falas ampliadas no qual os participantes se sintam a vontade para expressarem suas opiniões, seus medos, suas alegrias e seus sentimentos e assim compartilhando experiências uns com os outros ${ }^{(4)}$.

Diante do exposto, emergiu a seguinte pergunta nortedora do estudo: Qual a percepção dos usuários de dois Centro de Atenção Psicossocial (CAPS) quanto à roda de conversa? Para responder a pergunta noteadora, o presente estudo tem como objetivo descrever a percepção dos usuários de dois CAPS quanto à roda de conversa localizados na cidade de Maceió-AL.

\section{METODOLOGIA}

A pesquisa é transversal, descritiva e com abordagem qualitativa em que foi priorizada a fala dos usuários participantes. Os fatos foram observados, registra- 
dos, analisados, sem interferência das pesquisadoras; os indivíduos foram descritos com relação as suas características pessoais e suas histórias de fatores causais.

A coleta de dados foi realizada por meio de entrevistas, observações sistemáticas e registro em diário de campo, após a aprovação pelo Comitê de Ética em Pesquisa da Faculdade Estácio de Alagoas, sob n. ${ }^{\circ} 2.641 .730$ atendendo à Resolução n. ${ }^{\circ}$ 466/12 do Conselho Nacional de Saúde (CNS). Na ocasião das entrevistas, foi entregue o Termo de Consentimento Livre e Esclarecido (TCLE) aos participantes do estudo.

A pesquisa foi desenvolvida no Centro de Atenção Psicossocial III Álcool e outras drogas Dr. Everaldo Moreira, Centro de Atenção Psicossocial II Dr. Sadi Feitosa Carvalho, localizados no município de Maceió - Alagoas. Foram incluídos todos os usuários dos CAPS que aceitaram participar da pesquisa e que tinham no mínimo três meses ininterruptos ou mais em tratamento e que frequentavam com regularidade a roda de conversa. Foram excluídos os participantes que possuíam idade inferior a 18 anos e que estivessem sob o efeito de álcool e outras drogas ou em crise psicótica.

A aproximação com os usuários participantes foi realizada pessoalmente, as pesquisadoras se identificaram como estudantes do Curso de Enfermagem de uma instituição particular no município de Maceió. Foram explicitados dados referentes ao objeto de estudo, objetivos da pesquisa, entrevista semiestruturada, observação sistemática, registros em diário de campo e foi realizado o convite para participar da pesquisa. As confirmações da participação e das entrevistas foram agendadas ficando a escolha do dia, horário e atividade a seu critério.

Para coleta de dados, foram utilizadas duas estratégias: observação sistemática em diário de campo e entrevista semiestruturada. A entrevista semiestruturada foi realizada com cada participante da pesquisa em um lugar privativo escolhido por ele (a). As respostas e comentários foram gravados em um aparelho de áudio e tudo o que foi relatado e gravado foi transcrito e lido ao participante, o qual confirmou se as informações coincidiram ou não com o que ele (a) falou. Tudo estava em conformidade e foi autorizado pelo (a) participante da pesquisa o uso das informações para a pesquisa.

No que concerne ao roteiro de entrevista semiestruturada, é toda uma comunicação entre pessoas em que será realizada pelo entrevistador com objetivo de haver informações pertinentes para o objeto da pesquisa a ser realizada. Em relação à observação sistemática, designada também como estruturada, planejada e controlada, o observador se torna capaz de se pôr no lugar do outro, ele sabe o que procura em uma determinada situação(5).

Foi observado o momento da roda de conversa que são ministradas por profissionais da saúde e usuários (as) participantes dos CAPS, também foi utilizado um diário de campo onde foi possível registrar as impressões obtidas a partir das vivências de entrevista e observação sistemática. O diário de campo é um documento simples, e foi nele onde as entrevistadoras registraram informações relevantes, como: acontecimentos, comportamentos, conversas formais e informais que fossem a respeito do tema da pesquisa ${ }^{(6)}$.

Por se tratar de uma pesquisa que lida diretamente com pessoas, há riscos de estresse e abalo emocional, os quais foram minimizados através da manutenção da privacidade, confidencialidade e respeito ao participante da pesquisa. Os participantes não foram identificados, prezou-se pelo anonimato destes, utilizando a letra $U$ de usuário e números para identificá-los, seguindo a sequência de entrevistas (ex.: U1, U2, U3,...).

Este estudo possibilitou aos usuários participantes descreverem sobre a importância da roda de conversa para a sua promoção da saúde e reabilitação psicossocial.

Os dados foram analisados através da estratégia de análise de conteúdo do tipo categoria temática. A análise de conteúdo é um instrumento de pesquisas com vários tipos de aplicação e técnicas de análise das comunicações que irá interpretar o que foi relatado pelo entrevistado e atingir os objetivos propostos. Na análise do material, busca-se classificá-los em temas ou categorias que auxiliam na compreensão do que está por trás dos discursos.

A análise temática de conteúdo se divide em três etapas: pré-análise, exploração do material ou codificação e tratamento dos resultados obtidos/ interpretação.

Dentro da etapa de pré-análise, é o momento em que o entrevistador colhe os documentos e vai organizar ideias, formular hipóteses dos documentos coletados para serem analisados e elaborar os indicadores que fundamentam a interpretação final, é a fase da organização propriamente dita. Sendo que esta fase compreende primeiro à leitura flutuante, momento em que o entrevistador organiza os textos e documentos que foram coletados para serem analisados; e é nessa fase que podem surgir as hipóteses ou questão norteadora ${ }^{(7)}$. Por segundo, será a escolha dos documentos que consistem na definição do corpus da análise.

A terceira é a formulação das hipóteses a partir da leitura inicial dos dados coletados; a quarta é a elaboração de indicadores que interpretarão os materiais que foram coletados. Na fase de exploração do material ou codificação dos dados coletados são transformados em unidades as quais permitem uma explicitação do conteúdo expresso da coleta. E por final, a fase do tratamento dos resultados obtidos/interpretação dos dados brutos coletados que são organizados e agregados em unidades.

Com base na análise de dados, como conteúdo temático, foi realizada uma leitura dos depoimentos das entrevistas semiestruturadas, separando por tema em comum das falas dos participantes, interpretando o que foi mencionado, em seguida foi realizada uma exploração do material identificando as ideias com recortes de trechos e, por fim, realizou-se um embasamento teórico fundamentando a discussão e concluído com resultados encontrados da pesquisa ${ }^{(8)}$. 


\section{RESULTADOS E DISCUSSÃO}

Diante do objetivo de descrever a percepção dos usuários dos CAPS quanto à roda de conversa, chegou-se aos resultados aqui apresentados. Estes foram obtidos através da análise das transcrições das entrevistas e, na medida do possível, integrados aos registros da observação sistemática e das anotações de campo.

Ouvir os usuários participantes dos CAPS levantou interesse e foram evidenciadas através desta pesquisa as seguintes temáticas: A roda de conversa como um meio de interação e troca de experiências; A roda de conversa como uma ferramenta de apoio no convívio familiar e A roda de conversa como um apoio na prevenção das recaídas.

A roda de conversa como um meio de interação e troca de experiências

Um momento de conversa serve para a formação de um espaço onde haverá troca de experiências, de opiniões e aprendizados. A roda surge como um instrumento capaz de produzir conteúdos importantes para a vida dos indivíduos ao constituir um momento onde há falas e também escutas, havendo espaços de ajustar, aceitar, negar e/ou discordar ${ }^{(9)}$. Ainda de acordo com esse estudo, a roda funciona como um meio para construir informações e, ao mesmo tempo, fornecer dados para discussões.

A roda tem uma visão de unir pessoas com histórias de vida distintas, com a intenção de agrupar os indivíduos para tomada de decisões. As vozes desses usuários precisam ser escutadas e evidenciadas no dia a dia ${ }^{(8)}$.

U1: "Me sinto bem durante a roda de conversa e esse momento de interação com os outros usuários e profissionais foi onde eu aprendi a lidar com a doença".

U7: "A roda de conversa para mim é um meio de interagir com outras pessoas, pois sou muito tímido, eu também era muito isola- do e esses momentos que passo na roda tem me ajudado bastante" .

U13: "Acho a roda de conversa muito importante para o meu tratamento, com ela eu tenho mais conhecimento e aprendizado da minha doença".

A roda de conversa tem como propósito que as pessoas possam progredir, aprender, se expressar e se comunicar para superar os seus medos e entraves, proporcionando a junção dos sujeitos ao incentivar a comunicação interpessoal e a capacidade de resolver conflitos frente aos desafios de viver na sociedade. A roda tem como objetivo oportunizar a criação de diálogos e também tem uma visão de unir pessoas com histórias de vida distintas ${ }^{(10)}$.

As vozes desses usuários precisam ser escutadas e evidenciadas no dia a dia, pois são nesses encontros que haverá uma construção de histórias de grupos e individuais. É relevante que os usuários se permitam dialogar com os profissionais, $\mathrm{O}$ que possibilita trabalhar reflexivamente a respeito das manifestações apresentadas pelo grupo no saber lidar com sua doença.

A enfermagem tem um papel relevante no processo de interação e comunicação, permitindo que esses usuários utilizem essa comunicação como uma forma de ajudarem uns aos outros ${ }^{(11)}$.

O enfermeiro tem uma importante ferramenta que é a confiança, ela serve para que os usuários se sintam mais a vontade com o profissional diante do processo de interação e comunicação.

Se comunicar é um direito de qualquer pessoa, uma vez que a comunicação encontra um sentido de conforto, se tornando parte do tratamento, assim, a adequada comunicação se constitui numa ferramenta fundamental para o cuidado de enfermagem.

A roda de conversa como uma ferramenta de apoio no convívio familiar

A roda de conversa é um apoio para os usuários, porque é no momento da roda onde eles irão buscar orientação, meios e estratégias para melhorar o convívio familiar, compreendendo a importância da situação em que estão vivendo com o intuito de reduzir os conflitos que são causados com os familiares ${ }^{(12)}$.

U3: "Antes de começar a frequentar a roda de conversa me sentia triste e agitada, conforme fui frequentando a roda, tive mudanças no meu convívio familiar".

U4: "Participo da roda para ajudar em meu tratamento, é uma forma que eu me sinto livre e calmo, tive melhorias na convivência com minha mãe e minha irmã, a roda de conversa tem me ensinado muito, a saber, lidar com os conflitos familiares".

U8: "As rodas fazem bem para si próprio, houve mudança no meu convívio familiar, pois eu era muito bruto com eles no sentido geral".

U18: "Participo da roda para me acalmar, gosto de ouvir os profissionais dando conselhos, gosto de desabafar e aprendo ouvindo com os outros participantes, tive melhoras no meu convívio familiar após começar a participar da roda".

Muitos usuários dependentes do álcool e de outras drogas, e até mesmo psiquiátricos, têm muita dificuldade em manter um relacionamento saudável com os familiares, pois o preconceito em aceitá-los está presente em grande parte das famílias. A roda de conversa tem esse intuito, de quebrar barreiras de preconceito e enriquecer o tratamento desses usuários. A participação da família contribui bastante durante o tratamento do dependente químico ou psiquiátrico, pois é também na família que os usuários encontram proteção, determinação, confiança e ânimo para prosseguir com seu 
tratamento. O apoio familiar é importante no processo de reabilitação, isso acontece a partir da interação dos familiares junto à roda de conversa.

A enfermagem é importante tanto para os usuários como para seus familiares, pois proporciona um elo, a fim de contribuir e colaborar para sua reabilitação. É fundamental que o profissional de enfermagem estabeleça e mantenha o vínculo fundamentado em confiança para que o usuário e sua família possam falar de si e seus problemas com segurança.

Para Mariana ${ }^{(13)}$, o papel do enfermeiro em conjunto com uma equipe interdisciplinar é fundamental para a reabilitação dos usuários, gerando uma ligação com o mesmo e sua família, possibilitando, assim, que o profissional de enfermagem desenvolva com êxito seu papel e proporcione melhor assistência no tratamento dos usuários.

Rodas de conversa como uma ferramenta de auxílio nas recaídas

O espaço da roda de conversa intenciona a construção de novas possibilidades que se abrem ao pensar, num movimento contínuo de perceber - refletir - agir - modificar, em que os participantes podem se reconhecer como condutores de sua ação e da sua própria possibilidade de "ser mais"(4).

U17: "Me sinto fortalecido e motivado ao participar das rodas, se não existisse as rodas acho que teria mais recaídas".

U20: "As rodas tem me ajudado a me recuperar do vício, me sinto mais alegre".

U24: "As rodas para mim é uma forma de autoajuda, é onde eu me divirto, me desestresso, tem me ajudado nas recaídas do álcool".

U27: "As rodas tem me ajudado nas recaídas do álcool, é um meio de autoajuda para meu tratamento".
Os usuários reconhecem a importância da roda de conversa como uma ferramenta para seu tratamento, pois permite a troca de diferentes saberes, expressando seus conceitos, ideias, opiniões sobre algum tema que seja proposto na roda, configura-se num momento singular de partilha, fazendo com que eles tenham cada vez mais controle no momento das recaídas, obtendo mais alto nível de confiança para possibilitar mudanças de hábitos negativos ao proporcionar bem-estar e superação durante o tratamento, o que acarreta no êxito desse processo de reabilitação.

Segundo estudo ${ }^{(14)}$, a roda de conversa possibilita ao usuário o máximo de compreensão, pois tem como estratégia as dinâmicas de grupo, promovendo a participação entre os usuários, destacando os conhecimentos, comportamentos e práticas.

Para autores ${ }^{(15)}$, a ferramenta da roda tem como direção a comunicação por meio da conversa. Neste ambiente, as dúvidas e os sentimentos são compartilhados e, com isso, há uma troca de informações sobre o cuidado entre eles, permitindo reflexões, avaliação e alteração de hábitos.

Estudo $^{(14)}$ concorda com outra pesquisa $^{(15)}$, ao destacar que a roda de conversa tem como característica motivar os participantes a relatarem em conjunto as suas ideias, pontos de vista, opiniões e conceitos sobre o tema proposto, possibilitando lidar com as manifestações expostas pelo grupo.

Autores $^{(16)}$ se certificaram que as estratégias abordadas através das atividades, bem como a roda de conversa, artesanais e musicais, aprimoram a compreensão individual de cada participante, possibilitando o alcance da sua própria história, constituindo um novo universo para o diálogo e superando as dificuldades encontradas durante o tratamento.

A roda de conversa se compõe como uma ferramenta terapêutica que auxilia na reabilitação dos usuários dos CAPS, reduzindo as tensões relacionadas às cri- 
ses psicóticas e as recaídas do álcool e outras drogas no seu tratamento. A roda proporciona troca de ideias e experiências e um ambiente onde eles se sentem acolhidos e à vontade para expressar suas emoções, visando contribuir para a recuperação e reinserção na sociedade.

O enfermeiro desempenha um papel importante durante a roda de conversa, estabelecendo uma ligação e compreendendo os usuários, tanto em conjunto como na individualidade e necessidade de cada um, dessa forma, o usuário tem a oportunidade de, não só organizar seus pensamentos, mas também suas emoções, evitando possíveis recaídas.

No momento da roda de conversa, o enfermeiro tem a percepção de observar cada usuário e fazer avaliações clínicas e também elaborar um plano terapêutico de acordo com suas necessidades para o tratamento. Como enfermeiros, temos que mostrar à sociedade que é possível a reinserção social desses usuários que são excluídos da sociedade por serem dependentes de alguma droga ou álcool e/ou psiquiátricos.

\section{CONCLUSÃO}

A pesquisa deteve-se em descrever a percepção dos usuários dos CAPS quanto à roda de conversa. Observou-se que a roda de conversa funciona como um dis- positivo positivo para o cuidado e a promoção da saúde mental dos usuários dos CAPS. Diante do que foi exposto na fala dos usuários participantes, possibilitou-se detectar o quanto a roda de conversa é uma ferramenta essencial para o tratamento dos usuários.

As perguntas do roteiro de entrevista permitiram que os usuários descrevessem suas percepções quanto à roda de conversa, tais como: dificuldades no convívio familiar, dificuldades de interagir com outras pessoas e recaídas com o uso do álcool e drogas. Dada à importância do assunto, a roda de conversa serve como um instrumento de cuidado e promoção da saúde mental desses usuários.

\section{Referências}

1. Jorge BSM, et al. Promoção da Saúde Mental - Tecnologias do Cuidado: vínculo, acolhimento, co-responsabilização e autonomia. Revista Ciênc. Saúde coletiva [Internet]. 2011 [acesso em 22 set 2018]; 16(7): 3051-3060. Disponivel em: https://www.scielo.br/pdf/csc/ v16n7/05.pdf.

2. Ministério da Saúde, Secretaria de Atenção à Saúde, Departamento de Atenção Básica (BR). Saúde Mental /Brasília: Ministério da Saúde, 2013. Cadernos de Atenção Básica [Internet], n. 34, p.176 [acesso em 20 ago 2018]. Disponível em:

http://bvsms.saude.gov.br/bvs/publicacoes/cadernos_atencao_basica_34_saude_m ental.pdf.

3. Melo CMA. Apontamentos sobre a reforma psiquiátrica no Brasil. Cadernos Brasileiros de Saúde Mental [Internet]. 2012 [acesso em 01 set 2019]; 8(9):84-95. Disponível em: https://incubadora.periodicos. ufsc.br/index.php/cbsm/article/viewFile/2127/2920.

4. Sampaio J, et al . Limites e potencialidades das rodas de conversa no cuidado em saúde: uma experiência com jovens no sertão pernambucano. Interface Comunicação Saúde e Educação [Internet]. 2014 [acesso em 19 set 2019]; 18:1299-1311. Disponivel em: http://www. scielo.br/scielo.php?pid=S141432832014000601299\&script=sci_abstrac $t \&$ tlng=pt.

5. Ferreira V, Pereira I. 0 Desafio do Conhecimento: pesquisa qualitativa em saúde. JMPHC | Journal of Management \& Primary Health Care [Internet]. 2014 [acesso em 11 set 2019]; 5(2):258- 261. Disponível em: http://www.jmphc.com.br/jmphc/article/view/224.

6. Araújo LFS, et al. Diário de pesquisa e suas potencialidades na pesquisa qualitativa em saúde. Revista Brasileira de Pesquisa em Saúde [Internet]. 2013 [acesso em 15 mai 2018]; 15(1):53- 61. Disponível em: https://periodicos.ufes.br/RBPS/article/viewFile/6326/4660.

7. Cavalcante RB, Calixto P, Pinheiro MMK. Análise de Conteúdo: considerações gerais, relações com a pergunta de pesquisa, possibilidades e limitações do método. Revista Informação \& Sociedade: Estudos [Internet]. 2014 [acesso em 01 set 2019]; 24(1):13-18. Disponível em: http://www.periodicos.ufpb.br/index.php/ies/index.

8. Silva HA, Fossa TIM. Análise de conteúdo: exemplo de aplicação da técnica para análise de dados qualitativos. Qualitas revista eletrônica [Internet]. 2015 [acesso em 23 set 2019]; 16(1). Disponível em: http:// revista.uepb.edu.br/index.php/qualitas/article/view/2113/.

9. Moura AF, Lima MG. A reinvenção da roda de conversa: Um instru- mento metodológico possível. Revista Temas em Educação [Internet]. 2014 [acesso em 15 out 2018]; 23(1):98-106. Disponivel em: http:// www.periodicos.ufpb.br/index.php/rteo/article/view/18338/11399. 10. Tajra I. Roda de conversa como instrumento para criação de grupos de interação social e educacional em saúde-relato de experiência [Internet]. Trabalho de Conclusão de Curso Especialização Latu Sensu - TCC Educação Permanente em Saúde em Movimento - Universidade Federal do Rio Grande do Sul, 2015 [acesso em 15 out 2018]. Disponível em: http://eps.otics.org/alunos/piaui/subcop/pi-grupo-9/acervo/ roda-de- conversa-como-instrumento-para-criacao-de-grupos-de-interacao-social-e- educacional-em-saude-relato.

11. Siqueira C. Comunicação terapêutica em saúde mental. Revista Portuguesa de Enfermagem de Saúde Mental [Internet] 2014 [acesso em 22 out 2018]; 12(6). Disponível em: http://www.scielo.mec.pt/scielo.php?script=sci_arttext\&pid=S1647- 21602014000300001.

12. Minetto MF, Medina GB. Famílias em rodas de conversa sobre educar e incluir. Revista Infad de Psicologia [Internet]. 2017 [acesso em 22 out 2018]; 4(1): 87-96. Disponível em: http://www.infad.eu/RevistalNFAD/OJS/index.php/IJODAEP/article/view/1030/912.

13. Mariana C. $O$ cuidado na saúde mental: trabalho do enfermeiro no centro de atenção psicossocial [Internet]. 2015. 67 p. Trabalho de conclusão de curso em enfermagem- Centro Universitário UNIVATES, Lajeado, 2015 [acesso em 19 out 2018]. Disponivel em: https://www. univates.br/bdu/bitstream/10737/1187/1/2015MarianaCenci.pdf. 14. Melo RHV, et al. Roda de Conversa: uma articulação solidária entre ensino, serviço e comunidade. Revista Brasileira de Educação Médica [Internet]. 2016 [acesso em 22 out 2018]; 40(2):301-309. Disponível em: http://www.scielo.br/pdf/rbem/v40n2/1981-5271-rbem- 40-20301.pdf.

15. Costa RRO, et al. As rodas de conversa como espaço de cuidado e promoção da saúde mental. Revista de Atenção à Saúde [Internet]. 2015 [acesso em 01 set 2019]; 13(43):30-36. Disponível em:

http://seer.uscs.edu.br/index.php/revista_ciencias_saude/article/ view/26 75/pdf_1.

16. Batista EC, Ferreira DF. A música como instrumento de reinserção social na saúde mental: um relato de experiência. Revista Psicologia em Foco [Internet]. 2015 [acesso em 25 out 2018]; 7(1):1- 13. Disponível em: http://revistas.fw.uri.br/index.php/psicologiaemfoco/article/ view/1593/1940. 